\title{
Green manufacturing practices among wooden furniture manufacturers in Malaysia
}

\begin{abstract}
The adoption of green manufacturing practices by the Malaysian wooden furniture industry is limited as is shown by a questionnaire-based survey of wooden furniture manufacturers. The lack of price premium for green furniture products and the high cost involved in adopting such practices have been identified as the major restraints. Currently most green manufacturing practices are related to the use of environmental-friendly materials.
\end{abstract}

Keyword: Environmental-friendly, Furniture industry, Green manufacturing, High costs, Malaysia, Malaysians, Price premiums 